\title{
ANTIFUNGAL ACTIVITY OF CYMBOPOGON WINTERIANUS JOWITT EX BOR AGAINST CANDIDA
}

\section{ALBICANS}

\section{Wylly Araújo de Oliveira ${ }^{1,2^{*}}$, Fillipe de Oliveira Pereira ${ }^{1}$, Giliara Carol Diniz Gomes de Luna ${ }^{3}$, Igara Oliveira} Lima $^{1}$, Paulo Alves Wanderley ${ }^{4}$, Rita Baltazar de Lima ${ }^{5}$, Edeltrudes de Oliveira Lima ${ }^{1,3}$

${ }^{1}$ Laboratório de Tecnologia Farmacêutica, Centro de Ciências da Saúde, Universidade Federal da Paraíba, João Pessoa. PB, Brasil; ${ }^{2}$ Centro de Educação e Saúde, Universidade Federal de Campina Grande, Cuité, PB, Brasil; ${ }^{3}$ Laboratório de Micologia, Centro de Ciências da Saúde, Universidade Federal da Paraíba, João Pessoa, PB, Brasil; ${ }^{4}$ Instituto Federal de Educação, Ciência e Tecnologia da Paraíba, João Pessoa, PB, Brasil; ${ }^{5}$ Laboratório de Botânica, Departamento de Sistemática e Ecologia, Universidade Federal da Paraíba, João Pessoa, PB, Brasil.

Submitted: January 08, 2010; Returned to authors for corrections: May 22, 2010; Approved: November 04, 2010.

\begin{abstract}
Candida albicans is an opportunistic yeast and a member of the normal human flora that commonly causes infections in patients with any type of deficiency of the immune system. The essential oils have been tested for antimycotic activity and pose much potential as antifungal agents. This work investigated the activity of the essential oil of Cymbopogon winterianus against $C$. albicans by MIC, MFC and time-kill methods. The essential oil (EO) was obtained by hydrodistillation using a Clevenger-type apparatus. It was tested fifteen strains of C. albicans. The MIC was determined by the microdilution method and the MFC was determined when an aliquot of the broth microdilution was cultivated in SDA medium. The phytochemical analysis of EO showed presence of citronellal $(23,59 \%)$, geraniol $(18,81 \%)$ and citronellol $(11,74 \%)$. The EO showed antifungal activity, and the concentrations $625 \mu \mathrm{g} / \mathrm{mL}$ and $1250 \mu \mathrm{g} / \mathrm{mL}$ inhibited the growth of all strains tested and it was fungicidal, respectively. The antimicrobial activity of various concentrations of EO was analyzed over time, it was found concentration-dependent antifungal activity, whose behavior was similar to amphotericin B and nystatin.
\end{abstract}

Key words: Candida albicans, antifungal, Cymbopogon winterianus.

\section{INTRODUCTION}

Candida albicans is an opportunistic yeast and a member of the normal human flora. The individual is colonized at birth or near birth and transmission is primarily through physical contact. This yeast normally colonizes the skin and mucosal epithelium in healthy individuals (25). In patients hospitalized with cancer, immunocompromised or who use immunosuppressive drugs colonization may progress to invasion, resulting in severe systemic disease $(26,38)$.

*Corresponding Author. Mailing address: Pós-Graduação em Produtos Naturais e Sintéticos Bioativos/Laboratório de Tecnologia Farmacêutica/ Centro de Ciências da Saúde/ Universidade Federal da Paraíba-João Pessoa-Brasil ou Centro de Educação e Saúde/ Universidade Federal de Campina Grande-Cuité-Brasil.; E-mail: wyllybr@yahoo.com.br 
Systemic infection by $C$. albicans is often associated with catheters, surgery, parenteral nutrition and damage the skin, mucous membranes and the digestive tract (39). Invasive fungal infections are associated with high mortality rates and over $40 \%$ in bloodstream infections caused by C. albicans (8). The common sites for superficial candidiasis include under the breasts, in the groin, in skin folds of obese persons and the perineal area (18). The major antifungal agents used in the therapy of these infections are azoles such as fluconazole and itraconazole, and the polyene compounds such as amphotericin B and nystatin $(6,30)$.

The increasing resistance of fungi to azole derivatives as a result of long-term therapies may limit the use of these drugs in the future $(10,17,30)$. Due to limitations of current antifungal therapy and the emergence of resistant strains, it is necessary the search for new antifungal drugs through the testing of substances from plants $(3,34)$. Among the candidates, the essential oils are known to possess several biological activities, such as antibacterial and antifungal action $(2,7)$.

Cymbopogon winterianus is a plant belonging to the family Poaceae, popularly known as citronella, which is cultivated in India and Brazil. This plant demonstrated depressant effect on the central nervous system, anticonvulsant effect (33), larvicidal effect against Aedes aegypti (27), antibacterial (14,31) and antifungal activity (18), including anti-Candida action (13).

This study aimed to evaluate the antimicrobial activity of the essential oil of Cymbopogon winterianus against Candida albicans and to characterize the relationship between the concentration this essential oil with the rate and extent of its antifungal activity.

\section{MATERIAL AND METHODS}

\section{Essential oil}

Cymbopogon winterianus Jowitt ex Bor was grown, collected and had the essential oil extracted by hydrodistillation using a Clevenger-type apparatus at the Center for Technology Training at the Federal University of Paraíba, Bananeiras city (Paraiba, Brazil) by Prof. Dr. Paulo Alves Wanderley.

The plant was identified by Prof. Dr. Rita Baltazar de Lima in Laboratory of Botany, Department of Systematics and Ecology of the Center of Exact and Nature Sciences of the Federal University of Paraíba. The voucher specimen was deposited in the Herbarium Prof. Lauro Pires Xavier of the Department of Systematics and Ecology, Federal University of Paraíba under the code JPB 41387.

\section{Essential oil analysis}

The essential oil was analyzed using a gas chromatograph (GC) fitted to a mass spectrometer (MS) (GC-MS-Schimadzu QP-5050A) instrument equipped with a GC Schimadzu 17A. Fused silica capillary column was $30 \mathrm{~m}$ x $0.25 \mathrm{~mm}$ i.d., with film thickness $0.25 \mu \mathrm{m}$. Helium was used as the carrier gas at $0,9 \mathrm{~mL} / \mathrm{min}$, with inlet pressure 48,9 psi. Injector and MS transfer line temperatures were at 280 and $170^{\circ} \mathrm{C}$, respectively. The initial column temperature was $60^{\circ} \mathrm{C}$, and then gradually increased to $240^{\circ} \mathrm{C}$ at the rate of $3^{\circ} \mathrm{C} / \mathrm{min}$. It was kept at $240^{\circ} \mathrm{C}$ for 10 minutes. For GC-MS detection an electron ionization system was used with ionization energy of $70 \mathrm{eV}$. Samples were diluted $1 / 1000(\mathrm{v} / \mathrm{v})$ in hexane and $1.0 \mu \mathrm{L}$ were injected in the splitless mode (1). The compounds were identified by comparing their fragmentation patterns reported in the mass spectra with those present in the library of mass spectrometers NIST 98 (National Institute of Standards and Technology, USA) and with reports from the literature. The components quantification was based on the area percentage of the peak of each component in relation to the total area of all standardized peaks in the chromatogram.

\section{Fungal samples}

The strains of $C$. albicans tested belong to the collection of the Mycology Laboratory, Federal University of Paraíba and include ATCC 76485, ATCC 76615, ATCC 13803, LMV 42, 
ICB 12, M101, LM 968, LM 68, LM 16, LM 018, LM 023, LM 601, LM 290, LM 052, LM 087.

\section{Determination of minimum inhibitory concentration (MIC) and minimum fungicidal concentration (MFC)}

The MIC was determined by the microdilution method. Cultures of Candida albicans were placed on Sabouraud Dextrose Agar (SDA) and incubated for 24-72 hours at temperature $37^{\circ} \mathrm{C}$. Colonies of this culture were suspended in sterile $0.85 \% \mathrm{NaCl}$ and the inoculum was standardized according to the scale of 0.5 McFarland (1-5 x $10^{6} \mathrm{CFU} / \mathrm{mL}$ ). In a 96-well plate was added Sabouraud broth and essential oil of $C$. winterianus concentrations of 10.0000 to $39 \mu \mathrm{g} / \mathrm{mL}$. The MIC determination was conducted with approximately 1-5 $\mathrm{x} 10^{5} \mathrm{CFU} / \mathrm{mL}$ of the microorganism in each well. The plates were incubated at $37^{\circ} \mathrm{C}$ for $24-48$ hours. In $24-48$ hours there was a visual observation of fungal growth. To determine the MFC, $10 \mu \mathrm{L}$ of each of the wells without fungal growth was seeded on a plate containing SDA, the SDA plating were incubated at $37^{\circ} \mathrm{C}$ for $24-48$ hours. The MFC was considered as the lowest concentration cultivated in plate with SDA in which growth was less than 3 CFU. Afterwards, $20 \mu \mathrm{L}$ of $0.5 \%$ triphenyl tetrazolium chloride (TTC) was added to each of 96 wells for MIC determination, and the plate incubated for 24 hours. The MIC was determined as the lowest oil concentration that inhibited visible growth of the microorganism, as also indicated by the TTC by reading the plates of 96 wells. There were three independent experiments on different occasions (11, $15,21,40)$.

\section{Time-kill}

The time-kill of $C$. albicans in presence of the essential oil was performed according to Klepser et al. (22), with some modifications. Before testing, the microrgamism was cultivated in SDA. Colonies derived from culture were suspended in $0.85 \% \mathrm{NaCl}$ and turbidity adjusted to the range of 0.5 McFarland (1-5 x $\left.10^{6} \mathrm{CFU} / \mathrm{mL}\right)$. One milliliter of fungal suspension was added to $9 \mathrm{~mL}$ of broth Sabouraud with or without the essential oil in various appropriate concentrations. The initial inoculum contains $1-5 \times 10^{5}$ CFU/mL. Concentrations of essential oil of $C$. winterianus tested were $0.5,1,2,4$ and 8 times the MIC. These cultures were incubated at $37^{\circ} \mathrm{C}$ and at various time periods $(0,1,2,4,6,8,12$ and 24 hours), an aliquot of $100 \mu \mathrm{L}$ was removed from each solution and diluted 1:10. An aliquot of $10 \mu \mathrm{L}$ of each dilution was removed and plated on SDA. The plates were incubated at $37^{\circ} \mathrm{C}$ for $24-48$ hours and the number of colony forming units (CFU) was counted. When less than $1000 \mathrm{CFU} / \mathrm{mL}$ was expected, $10 \mu \mathrm{L}$ sample was plated directly into SDA without dilution. The experiment was performed in duplicate. The minimum detection limit of this method is $100 \mathrm{CFU} / \mathrm{mL}$ (23).

The $\log _{10} \mathrm{CFU} / \mathrm{mL}$ was plotted on a graph as function of time and used to compare the rate and extent of antifungal activity in various concentrations of essential oil. It was considered fungicidal activity when there was a decrease greater than or equal to $3 \log _{10} \mathrm{CFU} / \mathrm{mL}$ of the initial inoculum, resulting in reduction of $99.9 \%$ or more CFU/mL in 24 hours compared with the initial inoculum. Activity lower than that described was considered fungistatic $(16,24,35)$.

\section{RESULTS}

\section{Chemical characterization of oil constituents}

Essential oil of $C$. winterianus was subjected to GC and GC-MS analysis. The phytochemicals and their respective percentage in the essential oil composition and retention times are shown in Table 1 . The majority constituents were citronellal $(23,59 \%)$, geraniol $(18,81 \%)$ and citronellol $(11,74 \%)$.

\section{Determination of minimum inhibitory concentration (MIC) and minimum fungicidal concentration (MFC)}

By the broth microdilution technique was determined the MIC and the MFC, which are shown in Table 2. 
As seen in Table 2, the MIC of the essential oil tested ranged between 78 and $625 \mu \mathrm{g} / \mathrm{mL}$. The concentration of 625 $\mu \mathrm{g} / \mathrm{mL}$ inhibited the growth of all strains, while $312 \mu \mathrm{g} / \mathrm{mL}$ was able to inhibit $60 \%$ of the strains tested. MFC of microorganisms ranged between 312 and $1250 \mu \mathrm{g} / \mathrm{mL}$, being the latter fungicidal for all strains tested.

Table 1. Chemical composition of essential oil from $C$. winterianus.

\begin{tabular}{clcc}
\hline Peak No. & \multicolumn{1}{c}{ Compounds } & Composition $(\boldsymbol{\%})$ & Retention time $(\mathbf{m i n})$ \\
\hline 1 & 2-methyl-2-hepten-6-one & 0.13 & 6,99 \\
2 & $\beta$-myrcene & 0.07 & 7.18 \\
3 & Limonene & 3.39 & 8.58 \\
4 & Linalool & 1.34 & 11.13 \\
5 & Citronellal & 23.59 & 13.81 \\
6 & Citronellol & 11.74 & 17.00 \\
7 & Geraniol & 18.81 & 18.65 \\
8 & Citronellyl acetate & 5.29 & 22.30 \\
9 & $\beta$-elemene & 6.40 & 22.50 \\
10 & Eugenol & 10.34 & 23.96 \\
11 & Germacrene & 2.63 & 27.69 \\
12 & $\Delta$-cadinene & 2.27 & 29.44 \\
13 & Elemol & 6.73 & 30.67 \\
14 & Endo-1-bourbonanol & 1.01 & 31.52 \\
15 & Farnesol & 0.60 & 33.01 \\
16 & $\gamma$-eudesmol & 1.00 & 33.66 \\
17 & Torreyol & 1.65 & 34.08 \\
18 & Trans-farnesol & 3.01 & 34.69 \\
\hline
\end{tabular}

Table 2. Minimum inhibitory concentration (MIC) and minimum fungicidal concentration (MFC) of essential oil of $C$. winterianus against strains of C. albicans.

\begin{tabular}{ccc}
$\begin{array}{c}\text { C. albicans } \\
\text { samples }\end{array}$ & $\begin{array}{c}\text { MIC } \\
(\boldsymbol{\mu g} / \mathbf{m L})\end{array}$ & $\begin{array}{c}\text { MFC } \\
(\boldsymbol{\mu g} / \mathbf{m L})\end{array}$ \\
\hline 1- ATCC 76485 & 78 & 312 \\
2- ATCC 76615 & 78 & 312 \\
3- ATCC 13803 & 625 & 1250 \\
4- LMV 42 & 312 & 625 \\
5- ICB 12 & 625 & 1250 \\
6- M101 & 312 & 625 \\
7- LM 968 & 156 & 312 \\
8- LM 68 & 625 & 1250 \\
9- LM 16 & 625 & 1250 \\
10- LM 018 & 312 & 625 \\
11- LM 023 & 312 & 625 \\
12- LM 601 & 312 & 625 \\
13- LM 290 & 625 & 1250 \\
14- LM 052 & 312 & 625 \\
15- LM 087 & 625 & 1250 \\
\hline
\end{tabular}




\section{Time-kill}

The microorganism growth was analyzed over time when it was subjected to various concentrations of essential oil of $C$. winterianus. Two strains of C. albicans (ICB 12 and ATCC 13803) were submitted to the experiment of microbial time-kill (Figures 1 and 2).

The graphs show the $\log _{10}$ of $\mathrm{CFU} / \mathrm{mL}$ versus time for several multiples of the MIC $(625 \mu \mathrm{g} / \mathrm{mL})$ and the control without essential oil. The analysis of the graph to point out that at concentrations less than or equal to $1 \mathrm{xMIC}$, the essential oil has fungistatic activity (reduction of less than $99.9 \%$ or $3 \log _{10}$ the number of $\mathrm{CFU} / \mathrm{ml}$ of initial inoculum), and at concentrations greater than or equal to $2 \mathrm{xMIC}$ it has fungicidal activity (reduction greater than or equal to $99.9 \%$ or $3 \log _{10}$ the number of $\mathrm{CFU} / \mathrm{mL}$ of initial inoculum), therefore, the essential oil of $C$. winterianus has concentration-dependent fungicidal activity.

Although the rate and extent of antifungal activity has varied slightly between the two strains tested, their behavior in front of the essential oil was similar. The antifungal activity improved with increasing concentration of essential oil, like this, when the higher concentration of essential oil, the lower time is required for fungicidal activity.

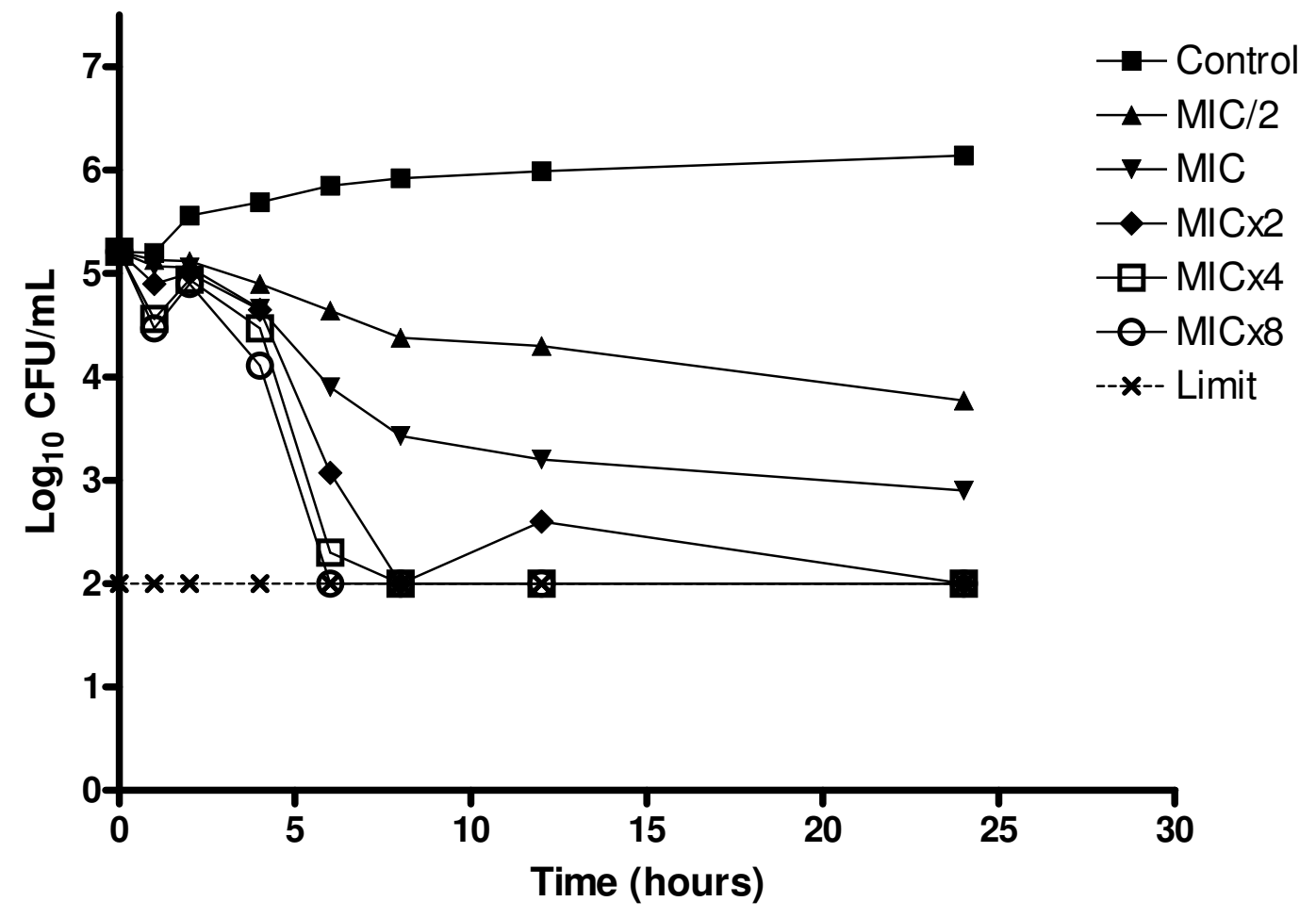

Figure 1. Time-kill of C. albicans ATCC 13803 when exposed to various concentrations of essential oil of $C$. winterianus. 


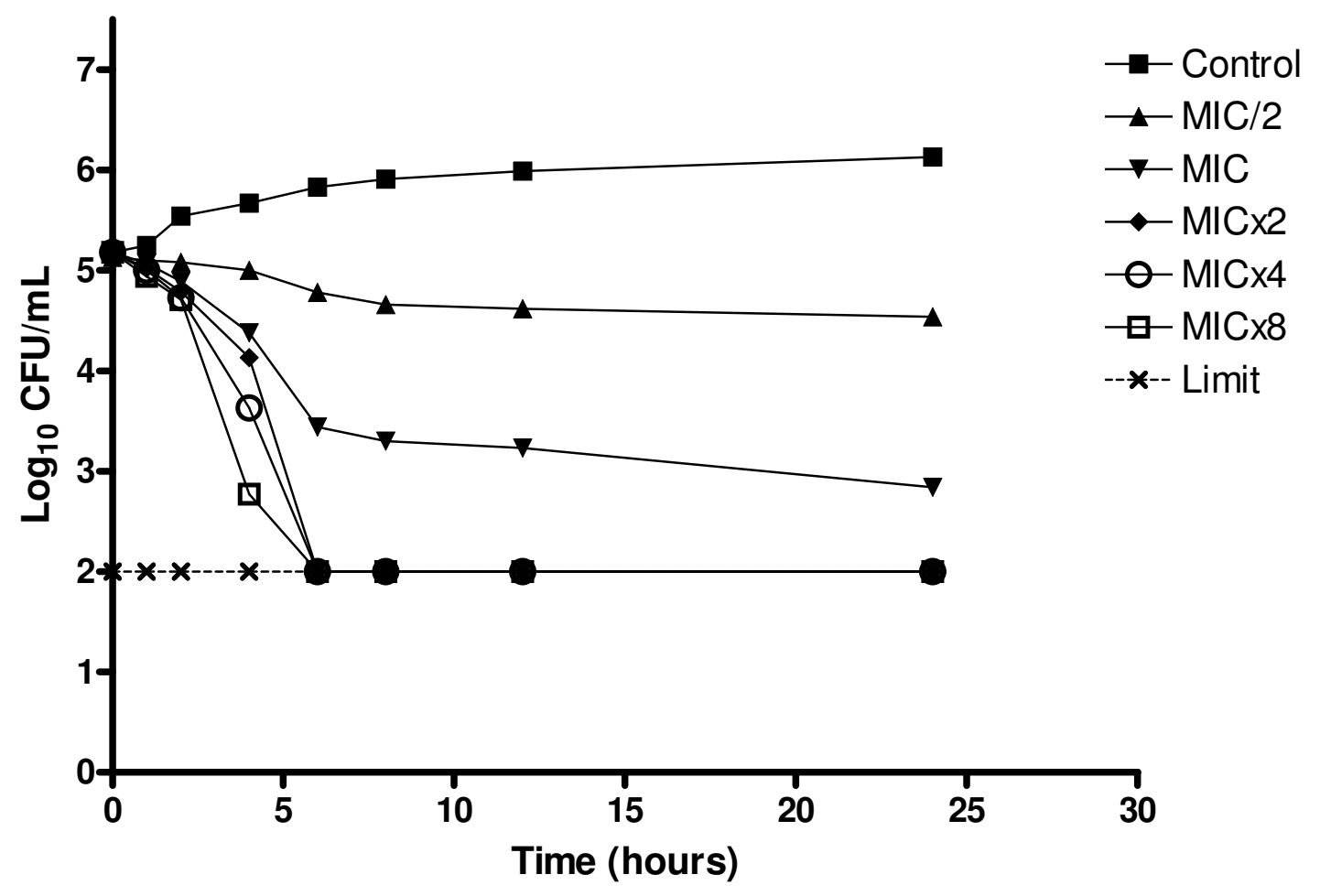

Figure 2. Time-kill of $C$. albicans ICB 12 when exposed to various concentrations of essential oil of $C$. winterianus.

\section{DISCUSSION}

Substances from plants are used in the treatment of various diseases, but the potential of plants as a source of new drugs is still poorly explored. The estimated number of plant species, only a small percentage had their pharmacological properties studied (34), like this, there is need to search for new drugs from plants that have therapeutic potential. Therefore, the essential oils are important because their several pharmacological activities including anti-fungal, antibacterial, antiparasitic $(2,4,37)$.

The GC-MS analysis resulted in the identification of 18 components. Among the phytochemicals, citronellal, geraniol and citronellol are the majority constituents. Other studies recorded that citronellal, citronellol and geraniol are the main constituents of essential oil of $C$. winterianus $(5,9,13,33)$.

Among the identified compounds, some were previously reported to have antibacterial activity, including geraniol against E. coli (14), Listeria monocytogenes, Salmonella enterica and Salmonella typhimurium (36). Mesa-Arango et al. (28) showed that citronellal and geraniol were active against Candida parapsilosis, C. krusei, Aspergillus flavus and A. fumigatus.

The MIC and the MFC in all strains were $625 \mu \mathrm{g} / \mathrm{mL}$ and $1250 \mu \mathrm{g} / \mathrm{mL}$, respectively. It was reported that the essential oil of this plant had antibacterial activity against Escherichia coli O157: H7 (MIC > 0,8\% v/v), Salmonella typhimurium (MIC 0,4\% v/v), Staphylococcus aureus (MIC 0,05\% v/v), Listeria monocytogenes (MIC 0,4\% v/v) (31); against enterotoxigenic, enteroinvasive and enteropathogenic serotypes of $E$. coli, with MICs ranging between 200 and $800 \mu \mathrm{g} / \mathrm{mL}$ (14) and antifungal activity against Trichophyton species (18) and

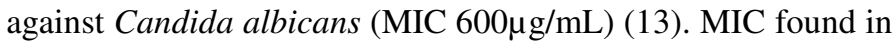
this study is according to values obtained in the other studies. 
Due to its pronounced anti- $C$. albicans activity, the essential oil of $C$. winterianus had its action studied in more detail through the time-kill method. When analyzing the graphic $\log _{10} \mathrm{CFU} / \mathrm{mL}$ versus time, it can identify the transition between the levels of fungistatic and fungicidal activity of a substance, the essential oil of $C$. winterianus showed concentration-dependent fungicidal activity. Another type of antifungal activity occurs for example with fluconazole, whose activity is independent of concentration, because there is no significant increase in activity with increasing concentration (6). Among the drugs commonly used to treat fungal infections, amphotericin B and nystatin are fungicidal concentration-dependent $(22,29)$.

It was reported that the essential oil of Ocimum gratissimum $\mathrm{L}$. had antifungal activity against $C$. albicans, $C$. krusei, C. parapsilosis and C. tropicalis with MICs ranging between 750 and $1500 \mu \mathrm{g} / \mathrm{mL}$ and in the test of time-kill this oil showed concentration-dependent antifungal activity (29).

The MFC found when an aliquot of the broth microdilution was cultivated in SDA medium was $1250 \mu \mathrm{g} / \mathrm{mL}$ (2xMIC). This value is related to the concentration able to inhibit the growth of $99.9 \%$ or more CFU/mL in 24 hours compared with the initial inoculum, information that can be observed analyzing the time-kill graphs.

Clinically, differences in fungal dynamics can influence the selection of optimal regimes of doses of an antifungal. Agents in which the rate and extent of antifungal activity improve with increasing concentration (e.g. amphotericin B) can be optimized by the administration of large doses. In contrast, the activity of antifungal agents like fluconazole does not improve with increase in the concentration higher than the MIC. Therefore, the administration of large doses of fluconazole cannot change the rate and extent of fungal eradication (16)

Pauli and Schilcher (32) suggest that oral administration of essential oil compounds is not suitable to cure severe infections in children. Topical application or inhalation of selected compounds for the treatment or additional treatment of mild infections is reasonable. Dorman and Deans (12) reported that administered orally, volatile oils may be able to control a wide range of microbes, but there is also the possibility that they may cause an imbalance in the gut microflora, allowing opportunistic pathogens coliforms to become established in the gastrointestinal tract with resultant deleterious effects. Other possible side effects of essential oils are irritation, allergic contact dermatitis and spasmolytic or spasmogenic properties (7). The essential can to be used for treatment some diseases like dermatomycoses and superficial candidiasis mainly in topical applications (18). The essential oils can be used alone or in combination with other drugs which can exhibit synergism $(19,20)$.

The increased resistance of $C$. albicans and the nature of the fungistatic azoles have valued the search for new antifungal agents, once the activity against this type of pathogen is essential (16). The antifungal activity demonstrated by the essential oil of $C$. winterianus makes it a potential candidate as a major agent in controlling fungi growth that cause infections or are present in the environment.

\section{ACKNOWLEDGEMENTS}

The authors are grateful to financial support from UFPB, CAPES and CNPq (Brazil).

\section{REFERENCES}

1. Adams, R. P. (2001). Identification of essential oils components by gas chromatography/quadrupole mass spectroscopy. Allured Publishing Corporation, Illinois, USA.

2. Bakkali, F.; Averbeck, S.; Averbeck, D.; Idaomar, M. (2008). Biological effects of essential oils - a review. Food Chem. Toxicol. 46,446-475.

3. Barrett, D. (2002). From natural products to clinically useful antifungals. Biochim. Biophys. Acta. 1587, 224-233.

4. Barros, J. C.; Conceição, M. L.; Neto, N. J. G.; Costa, A. C. V.; Siqueira Júnior, J. P.; Basílio Júnior, I. D.; Souza, E. L. (2009). Interference of Origanum vulgare L. essential oil on the growth and some physiological 
characteristics of Staphylococcus aureus strains isolated from foods. Food Sci. Technol. 42, 1139-1143.

5. Blank, A. F.; Costa, A. G.; Arrigoni-Blank, M. F.; Cavalcanti, S. C. H.; Alves, B. P.; Innecco, R.; Ehlert, P. A. D.; Sousa, I. F. (2007). Influence of season, harvest time and drying on Java citronella (Cymbopogon winterianus Jowitt) volatile oil. Braz J Pharmacogn. 17(4), 557-564.

6. Burgess, D. S.; Hastings, R. W.; Summers, K. K.; Hardin, T. C.; Rinaldi, M. G. (2000). Pharmacodynamics of fluconazole, itraconazole and amphotericin B against Candida albicans. Diagn. Micr. Infec. Dis. 36, 13-18.

7. Burt, S. (2004). Essential oils: their antibacterial properties and potential applications in foods - a review. Int. J. Food Microbiol. 94, 223-253.

8. Canuto, M. M.; Rodero, F. G. (2002) Antifungal drug resistence to azoles and polyenes. Lancet Infect. Dis. 2, 550-563.

9. Cassel, E.; Vargas, R. M. F. (2006). Experiments and modeling of the Cymbopogon winterianus essential oil extraction by steam destilation. $J$. Mex. Chem. Soc. 50 (3), 126-129.

10. Cernicka, J.; Subik, J. (2006). Resistance mechanisms in fluconazoleresistant Candida albicans isolates from vaginal candidiasis. Int. J. Antimicrob. Ag. 27, 403-408.

11. Costa, E. V.; Teixeira, S. D.; Marques, F. A.; Duarte, M. C. T.; Delarmelina, C.; Pinheiro, M. L. B.; Trigo, J. R.; Maia, B. H. L. N. S. (2008). Chemical composition and antimicrobial activity of the essential oils of the Amazon Guatteriopsis species. Phytochemistry. 69, 18951899.

12. Dorman, H. J. D.; Deans, S. G. (2000) Antimicrobial agents from plants: antibacterial activity of plant volatile oils. J. Appl. Microbiol. 88, 308-316.

13. Duarte, M. C. T.; Figueira, G. M.; Sartoratto, A.; Rehder, V. L. G.; 28. Delarmelina, C. (2005). Anti-Candida activity of Brazilian medicinal plants. J. Ethnopharmaco.. 97, 305-311.

14. Duarte, M. C. T.; Leme, E. E.; Delarmelina, C.; Soares, A. A.; Figueira, G. M.; Sartoratto, A. (2007). Activity of essential oil from Brazilian medicinal plants on Escherichia coli. J. Ethnopharmacol. 111, 197-201.

15. Ernst, E. J.; Klepser, M. E.; Ernst, M. E.; Messer, S. A.; Pfaller, M. A (1999). In vitro pharmacodynamic properties of MK-0991 determined by time-kill methods. Mycology. 33, 75-80.

16. Ernst, M. E.; Klepser, M. E.; Wolfe, E. J.; Pfaller, M. A. (1996). Antifungal dynamics of LY 303366, an investigacional echinocandin B analog, against Candida ssp. Diagn. Micr. Infec. Dis. 26, 125-131.

17. Gualco, L.; Debbia, E. A.; Bandettini, R.; Pescetto, L.; Cavallero, A.; Ossi, 3 M. C.; Schito, A. M.; Marchese, A. (2007). Antifungal resistence in Candida spp. isolated in Italy between 2002 and 2005 from children and adults. Int. J. Antimicrob. Ag. 29, 179-184.

18. Harris, R. (2002). Progress with superficial mycoses using essential oils. 32. Int. J. Aromath. 12(2), 83-91.
19. Harris, R. (2002). Synergism in the essential oil world. Int. J. Aromath. 12(4), 179-186.

20. Hemaiswarya, S.; Kruthiventi, A. K.; Doble, M. (2008). Synergism between natural products and antibiotics against infectious diseases. Phytomedicine. 15, 639-652.

21. Klepser, M. E.; Ernst, E. J.; Ernst, M. E.; Messer, S. A.; Pfaller, M. A. (1998). Evaluation of endpoints for antifungal susceptibility determinations with LY303366. Antimicrob. Agents Chemother.42 (6)1387-1391.

22. Klepser, M. E.; Wolfe, E. J.; Jones, R. N.; Nightingale, C. H.; Pfaller, M. A. (1997). Antifungal pharmacodynamic characteristics of fluconazole and amphotericin B tested against Candida albicans. Antimicrob. Agents Chemother. 41 (6), 1392-1395.

23. Klepser, M. E.; Wolfe, E. J.; Pfaller, M. A. (1998). Antifungal pharmacodynamic characteristics of fluconazole and amphotericin B against Cryptococcus neoformans. J. Antimicrob. Chemother. 41, 397401.

24. Lewis, R. E.; Klepser, M. E.; Pfaller, M. A. (2000). In vitro pharmacodynamic characteristics of flucytosine determined by time-kill methods. Diagn. Micr. Infec. Dis. 36, 101-105.

25. Lott, T. J.; Fundyga, R. E.; Kuykendall, R. J.; Arnold, J. (2005). The human commensal yeast, Candida albicans, has an ancient origin. Fungal Genet. Biol. 42, 444-45.

26. McCullough, M. J.; Ross, B. C.; Reade, P. C. (1996). Candida albicans: a review of its history, toxonomy, epidemiology, virulence attributes, and methods of strain differentiation. Int. J. Oral Max. Surg. 25, 136-144.

27. Mendonça, F. A. C.; Silva, K. F. S.; Santos, K. K.; Ribeiro Júnior, K. A. L.; Sant'ana, A. E. G. (2005). Activities of some Braziliam against larvae of the mosquito Aedes aegypty. Fitoterapia. 76, 629-636.

Mesa-Arango, A. C.; Montiel-Ramos, J.; Zapata, B.; Durán, C.; Betancur-Galvis, L.; Stashenko, E. (2009). Citral and carvone chemotypes from the essential oils of Colombian Lippia alba (Mill) N.E. Brown: composition, cytotoxicity and antifungal activity. Mem. Inst. Oswaldo Cruz. 104(6), 878-884.

29. Nakamura, C. V.; Ishida, K.; Faccin, L. C.; Dias Filho, B. P.; Cortez D. A. G.; Rozental, S.; Souza, W.; Ueda-Nakamura, T. (2004). In vitro activity of essential oil from Ocimum gratissimum L. against four Candida species. Res. Microbiol. 155, 579-586.

30. Navarro-García, F.; Sánchez, M.; Nombela, C.; PLA, J. (2001). Virulence genes in the pathogenic yeast Candida albicans. FEMS Microbiol. Rev. 25, 245-268.

1. Oussalah, M.; Caillet, S.; Saucier, L.; Lacroix, M. (2007). Inhibitory effects of selected plant essential oils on the growth of four pathogenic bacteria: E. coli O157:H7, Salmonella typhimurium, Staphylococcus aureus and Listeria monocytogenes. Food Control. 18, 414-420.

Pauli, A.; Schilcher, H. (2004). Specific selection of essential oil compounds for treatment of children's infection diseases. 
Pharmaceuticals. 1, 1-30.

33. Quitans-Júnior, L. J.; Souza, T. T.; Leite, B. S.; Lessa, N. M. N.; Bonjardim, L. R.; Santos, M. R. V.; Alves, P. B.; Blank, A. F.; Antoniolli, A. R. (2008). Phytochemical screening and anticonvulsivant activity of Cymbopongon winterianus Jowitt (Poaceae) leaf essential oil in Rodents. Phytomedicine. 15, 619-624.

34. Rates, S. M. K. (2001).Plants as source of drugs. Toxicon. 39, 603-613.

35. Roling, E. E.; Klepser, M. E.; Wasson, A.; Lewis, R. E.; Ernst, E. J.; Pfaller, M. A. (2002). Antifungal activities of fluconazole, caspofungin (MK 0991), and anidulafungin (LY 303366) alone and in combination agaist Candida spp. and Cryptococcus neoformans via time-kill methods. Diagn. Micr. Infec. Dis. 43, 13-17.

36. Si, W.; Gong, J.; Tsao, R.;Zhou, T.; Yu, H.; Poppe, C.; Johnson, R.; Du, Z. (2006). Antimicrobial activity of essential oils and structurally related synthetic food additives towards selected pathogenic and beneficial gut bacteria. J. Appl. Microbiol. 100, 296-305.
37. Souza, E. L.; Stamford, T. L. M.; Lima, E. O.; Barbosa-Filho, J. M.; Marques. O. M. (2008). Interference of heating on the antimicrobial activity and chemical composition of Origanum vulgare L. (Lamiaceae) essential oil. Ciênc. Tecnol. Aliment. 28 (2), 418-422.

38. Viscoli, C.; Girmenia, C.; Marinus, A.; Collete, L.; Martino, P.; Vandercam, B.; Doyen, C.; Lebeau, B.; Spence, D.; Krcmery, V.; De Pauw, B.; Meunier, F. (1999). Candidemia in cancer patients: a prospective, multicenter surveillance study by the invasive fungal infection group (IFIG) of the European Organization for Research and Treatment of Cancer (EORTC). Clin. Infect. Dis. 28, 1071-1079.

39. Wroblewska, M. M.; Swoboda-Kopec, E.; Rokosz, A.; Krawczyk, E.; Marchel, H.; Luczak, M. (2002). Epidemiology of clinical isolates of Candida albicans and their suceptibility to triazoles. Int. J. Antimicrob. Ag. 20, 472-475

40. Zaror, L.; Espinel-Ingroff, A. (1989). Pruebas de susceptibilidad fungica frente a antimicoticos. Bol. Micol. 4 (2), 77-90. 